\title{
Survey of Industrial, Agricultural, and Medical Applications of Radiometric Gauging and Process Control
}

\section{J. H. Hubbell}

National Institute of Standards and Technology, Gaithersburg, MD 20899

\author{
Photon and particle radiations \\ (gamma rays, $x$ rays, brems- \\ strahlung, electrons and other \\ charged particles, and neutrons) \\ from radioactive isotopes, $x$-ray \\ tubes, and accelerators are now \\ widely used in gauging, production \\ control, and other monitoring and \\ metrology devices where avoidance \\ of mechanical contact is desirable. \\ The general principles of radiation \\ gauges, which rely on detection of \\ radiation transmitted by the sample, \\ or on detection of scattered or \\ other secondary radiations pro- \\ duced in the sample, are discussed.
}

\begin{abstract}
Examples of such devices currently used or at least shown to be feasible in industrial, transportation, building, mining, agricultural, medical, and other metrology situations are presented, drawing from a total of 146 selected technical and review paper reference sources here cited.
\end{abstract}

Key words: albedo; density; electrons; gamma rays; gages; gauges; metrology; moisture; neutrons; radiation; radiometric; thickness; transmission; $x$ rays.

Accepted: October 22, 1990

\section{Introduction}

Radiometric gauging is a powerful and generally noninvasive, nondestructive metrology tool used in a variety of industrial, agricultural, and medical human enterprises. Not only the industrialized nations, but also many less-developed countries have found this "high tech" (radiation physics) methodology to be readily adaptable to regional metrology needs following various indigenous original developments.

The radiations usually employed in radiometric gauging and control devices are photons ( $x$ rays, gamma rays, bremsstrahlung), electron beams (beta rays), neutrons, and, more rarely, alpha and other heavy charged particles. Types of gauges include transmission gauges, albedo (backscatter) gauges, $\mathrm{x}$-ray fluorescence gauges, and other devices employing a variety of radiation physics, atomic physics, and nuclear physics principles, sometimes rather exotic such as the Mossbauer effect. Radio- metric gauging and control devices have been reviewed by a number of authors, including, for example, Taylor [1], Palmer [2], Bock [3], Snow and Morris [4], Hubbell [5,6], and Clayton [7]. A review specializing in geology, mining, and metallurgy has been given by Kartashev [8], and on radiometric gauging in Portugal by Salgado et al. [9]. The International Organization for Standardization (ISO) [10] has developed and issued a Standard for design and application of radionuclide gauges, which is also a good source of information.

\section{General Principles of Radiometric Gauging and Control}

Radiation gauges necessarily involve a radiation source, surrounded by appropriate shielding to minimize any health hazard, plus usually a collima- 
tor to confine the radiation to a narrow beam as it impinges on the material sample. The other essential element of the gauge is a radiation detector, usually energy-selective, and also collimated and shielded, and associated electronics, as described, for example, in the level-gauging paper by Heier [11]. General approaches to the design, optimization, calibration, and error sources of both static (sample properties remain constant during measurement period) and dynamic (sample properties change during measurement) radiation gauges have been given by Urbanski [12,13], Henderson and McGhee [14], Notea and Segal [15,16], Zav'yalkin and Osipov [17], and Kasi [18].

In transmission (attenuation) gauges, as recently discussed by Bernhardt [19] and Oyedele [20,21] in the context of sheet-material production thickness control, the detector is located so as to directly "see" the collimated beam of radiation with intensity $I_{0}$ from the source. The sample is then interposed in the beam with surfaces normal to the beam direction, resulting in attenuation of the detector signal to an intensity $I$, for photons exponentially related to the sample thickness $t$ (in mass per unit area) according to

$$
I / I_{0}=\exp (-(\mu / \rho) t)
$$

where $\mu / \rho$ (in area per unit mass) is the mass attenuation coefficient for the sample material. Hence, for example, the mass per unit area thickness $t$ of a sample can be determined as

$$
t=\left[\ln \left(I_{0} / I\right)\right] /(\mu / \rho)
$$

from measurements of photon ( $\mathrm{x}$ ray or gamma ray) intensities $I_{0}$ (no sample in beam) and $I$ (sample in beam) and a knowledge of photon $\mu / \rho$ data from published tables such as those of Hubbell [22], Berger and Hubbell [23], or Cullen et al. [24].

Scatter gauges for density and thickness measurements are also widely used, usually relying on photon Compton scattering, the energy-angle relationship for this process, and the dependence of this process on electron density in the sample, as discussed by Taylor and Kansara [25,26], Pandey [27], Gayer et al. [28], and Zabrodskii [29,30,31]. Although the detector, which may be either on the same or far side of the sample from the radiation source, is usually collimated to restrict the detector view, in some monitoring devices neither the source nor the detector is collimated. When the detector and source are on the same side of the sample, the device is known as an albedo or backscatter gauge. Golikov et al. [32] have de- scribed a sheet-collimation gamma-ray albedo gauge for multi-layer structures, and Mohammadi [33] describes both gamma and electron-albedo gauges for measurement of glass container wall thickness.

Although $\mathrm{x}$-ray fluorescence (XRF) is more widely used for chemical analysis than for gauging, XRF is sometimes used as a type of albedo gauge for thickness measurements of thin films and coatings as discussed, e.g., by Saneyoshi et al. [34]. Analogous to XRF but involving atomic nuclei instead of atomic electron shells is the use of neutrons and the resultant gamma rays from inelastic scattering, radiative capture, and other nuclear interactions, for materials monitoring, as discussed by Pekarski [35]. Included in the variety of other radiation gauging and monitoring devices is detection of positron annihilation radiation for determination of mean radius and concentration of micropores in porous materials such as ceramics and powdered alloys as discussed by Semenov [36]. Radiographic determination of thickness variations using film detectors has been discussed by Lahure [37], and a good overview of neutron radiography and gauging can be obtained from the papers in an ASTM conference proceedings edited by Berger [38].

\section{Radiometric Gauging and Control in In-Plant Industries}

Computer aided (or axial) tomography (CAT scanning), first finding its dramatic application in medical diagnostic radiography, is now finding wide and very advantageous use in on-line dimensional, shape, and flaw-detection gauging and production control in in-plant industrial situations, as discussed by Morgan [39], Martz et al. [40], Seshadri et al. [41], and Altukhov et al. [42]. A somewhat simpler large-object flaw-detection device, using a thin fan-beam photon source and a one-dimensional array of silicon detectors has been described, e.g., by Gusev et al. [43].

In in-plant industries, an accurate knowledge of the level of material inside closed tanks is frequently required. Several kinds of radiometric level gauges are in use, including gamma transmission gauges (e.g., Apelblat [44] and Amberger and Heier [45]), gamma albedo gauges (e.g., Ochiana et al. [46]), and neutron albedo level gauges which are particularly well-suited to hydrogenous substances (Mathew et al. [47]). A linear-detection radiometric liquid-level gauge employing an array of sources (e.g., ${ }^{137} \mathrm{Cs}$ ) has been described by Gläser and 
Emmelmann [48]. When the material in the tank is radioactive, the level gauge consists of the detector only (Dickstein and Notea [49]), since the sample is also the radiation source.

Techniques for radiometric bulk density measurements of powdered process materials are reviewed by Thyn and Pokorny [50], and for density distribution measurements in dynamic high-temperature systems by Kondic and Lassahn [51]. Gamma-ray transmission measurements can be used in tubing-wall thickness monitoring (e.g., Frevert [52,53]), and gamma albedo tubing coating thickness measurements are described by Kapranov et al. [54]. A number of coating-thickness radiometric measurement techniques are available, including a scheme described by Grupper [55] utilizing a positron emitting radionuclide source, in which the positron absorption in the coating is measured by detecting the annihilation radiation. A more widely-used coating and thin film measurement technique is X-ray fluorescence (XRF) as described, for example, by Salmi et al. [56], Singh et al. [57], Kaushik et al. [58], Luzzi et al. [59], and Kowalska and Urbanski [60]. A related technique for thin film thickness measurement is PIXE (particle-induced $\mathrm{x}$-ray emission) as described by Miranda et al. [61] and compared with RBS (Rutherford backscattering, using ions with energy of the order of $0.5 \mathrm{MeV}$ ) by Oliver and Miranda [62].

A microcomputer-based gamma absorption gauge for routine production control of profiled rubber strip, also a beta-absorption monitor control for production of plastic foil in the 20 to $35 \mu \mathrm{m}$ thickness range, have been described by Tabor et al. [63]. In steel sheet hot rolling, $x$-ray transmission gauges are now used almost exclusively for roller control to achieve and maintain thickness dimension within desired tolerances as described, e.g., by Petushkov et al. [64] and by Firstov et al. [65]. A neutron gauge for determining acid concentrations in industrial pipelines has been described by Mirowicz and Lis [66], in which the hydrogen content in the acid solution is inferred from the slowing down of fast neutrons from a $\mathrm{Pu}-\mathrm{Be}$ source and detection of thermal neutrons. For dynamic thickness measurements of liquid films, a tracer technique using technetium $99 \mathrm{~m}$, for industrial application, has been described by Stopporka et al. [67]. On-stream analysis of material flowing in pipes, including chemical information, by energydispersive $\mathrm{X}$-ray fluorescence, has been discussed by Donhoffer [68].

For two-phase flow within pipes, Oyedele $[69,70]$ has studied the effect of void distributions on void determination using a gamma transmission gauge. Lin et al. [71] have described a pulsed photon activation (PPA) technique for nonintrusive measurements of single- and two-phase flows in a horizontal pipe. For measuring void fraction in a vertical pipe containing a flowing air-water mixture, Wang and Shih [72] describe a technique utilizing a bromine-82 gamma-ray source and a $\mathrm{NaI}(\mathrm{Tl})$ scintillation detector. Hussein [73] has described a neutron scattering system ("scatterometer") for measuring the void fraction in a gas-liquid flow, and Hussein and Waller [74] have also incorporated this device into a steam-quality meter in a fluidized bed plant, in which coal is burned with limestone in a "bed" suspended in air in a combuster.

To answer the demand for production quality control of new high-performance reinforced plastics, Entine et al. [75] have developed an x-ray transmission and scattering device for analytical measurement of the glass, graphite, and other fillers used in these plastics. In the fabrication of laser fusion targets, small spherical capsules containing deuterium-tritium, for the Lawrence Livermore National Laboratory (LLNL) Inertial Confinement Fusion (ICF) program, the absorption of liquid into a foam needed to be characterized, which proved to be amenable to an x-ray radiographic (vidicon) technique described by Rikard and Streit [76].

\section{Radiometric Gauging and Control in Transportation and Building Industries}

A current problem in the cargo and passenger air transport industry is the reliability of the fuel quantity gauging (FQG) systems aboard aircraft. Present aircraft FQG systems are based on the old capacitance gauges which sometimes suffer from fouling and electrical noise problems. Singh et al. [77] and Singh [78] have demonstrated the feasibility of a gamma-ray attenuation gauge using a weak ${ }^{241} \mathrm{Am}(59.5 \mathrm{keV})$ collimated radiation source and a colinear collimated detector capable of continuously monitoring the fuel quantity in the aircraft tanks to an accuracy of better than $1 \%$.

In the transport industries the density of highway concrete is related to its durability, and a twochannel gamma albedo density gauge is described by Groshev and Zabrodski [79] in which one detector views the highway surface where the gamma beam enters, and the other detector views a scattering volume below the surface. Another gamma albedo gauge, for assessing the density of concrete in both fresh and hardened states, consists 
of an uncollimated source and detector arrangement (Adil [80]). For measuring the density of the asphalt layer (thin lift) laid down on a repaved highway, a special gamma albedo gauge was developed by Dunn and Hutchinson [81]. A rather interesting example of radiometric gauging in the railway transport industries is gamma-ray albedo examination of railway ties (sleepers) for termite damage (Fookes et al. [82]).

Pipeline transport of solids in a slurry form can be a useful alternative to road and rail transport in terms of exhaust-fume air-pollution, vehicular accidents, and other hazards, as well as possible economic advantages in some cases. In the most usual situation in which the particles are denser than the fluid, for horizontal flow the concentration of solid particles is higher near the bottom of the pipe, resulting in a higher erosion rate in the bottom inside surface of the pipe than in the sides and top. Rohella [83] has demonstrated and described a gamma-ray attenuation device for measuring and monitoring both the chord-average concentration of solids in the flowing slurry, which determines the pipeline capacity, and the concentration gradient which affects the pipeline longevity.

In the building construction industry, an important parameter is the density of rock, soil, and other materials, characterizing a given building site, to be disturbed and to support the building. Henderson and McGhee [84,85] have mathematically modelled a gamma-ray backscattering (albedo) gauge using ${ }^{137} \mathrm{Cs}(0.66 \mathrm{MeV})$ or ${ }^{60} \mathrm{Co}(1.17,1.33 \mathrm{MeV})$ sealed "not too powerful" (e.g., $74 \mathrm{MBq}$ ) radiation sources for probing near-surface rock and soil densities without the need of the boreholes required in transmission gauging. For examining concrete walls in existing buildings, particularly for the presence, quantity, size, and position of steel reinforcing bars (rebar), and also for voids, Hussein and Whynot [86] and Tuzi and Sato [87] have demonstrated and described Compton-scattering gammaray single-scatter albedo probes. Such probes examine the small volume which is the common volume of intersection of the projections of the source collimator and the detector collimator, axially intersecting inside the concrete wall material, which volume can then be characterized by its density and other gamma-ray Compton scattering properties. If these collimator projections inside the concrete wall can be approximated by right circular cylinders of unequal or equal radii, this intersection volume may be obtained from formulas or a table given by Hubbell [88].

\section{Radiometric Gauging and Control in the Mineral Industries}

In addition to the work by Kartashev [8] mentioned earlier, a good overview of applications of radiometric gauging and control in the mineral industries is the report given by Watt [89] at the Fifth Pacific Basin Nuclear Conference (PBNC-5, 1985) in Seoul. The radiation physics basis for devices for formation lithology logging (well logging) with gamma rays, including Compton scattering and photoelectric absorption, is outlined by Bertozzi et al. [90].

In coal mining, an advance coal-degasification technique is used to remove much of the methane gas trapped in coal seams prior to the mining process in order to reduce the possibility of explosions during mining. In this technique, boreholes approximately $10 \mathrm{~cm}$ in diameter are drilled as deep as 600 $m$ into the working faces of the mine. The methane gas permeates through the coal into the boreholes, from which as much as $50 \%$ of the methane in the seam can be captured and safely removed. A major obstacle in this technique is that coal seams are in general not straight, requiring periodical removal of the bit and taking of core samples to be sure that the bit has not left the seam. The drill strings used for this process have hydraulically powered drill bits which can be steered slightly into a curved drill path chosen by the operator. To provide steering information to the operator, Entine et al. [91] have developed and demonstrated a CdTe solidstate detector probe, mounted adjacent to the drill tip, which detects the natural radioactivity (usually of uranium, with gamma rays of several hundred $\mathrm{keV}$ energy) in the shale outside the seam, and hence the nearness of the drill bit to the seam edgeregion where, incidentally, is also found the coal highest in both ash and sulfur content.

On-stream and bulk analysis radiometric devices for probing iron and other ores on moving conveyor belts, using a variety of radiations including gamma rays and both fast and thermal neutrons have been described by Holmes [92] and by Borsaru et al. [93]. A time-of-flight fast-neutron probe useful not only for coal analysis and oil shale assay, but also adaptable to detection of contraband drugs and explosives, has been successfully demonstrated by Gordon and Peters [94].

Production of synthetic crudes is currently receiving some attention, since depletion of natural crudes is effectively irreversible, and because political and now military turmoil has rendered highly 
uncertain some major sources of imported natural crudes. One of the processes being developed by CANMET (Canada Centre for Mineral and Energy Technology, Ottawa) to produce synthetic crudes by upgrading heavy oils, refinery residua, tar sand bitumen, and coal, is by adding hydrogen to increase the $\mathrm{H} / \mathrm{C}$ ratio by various techniques, such as hydrocracking, all of which require high temperatures and pressures and close monitoring of the multi-phase hydrodynamic activity inside closed chemical reactors. Liu and Patmore [95] have demonstrated a ${ }^{137} \mathrm{Cs}$ gamma-ray attenuation scanning densitometer on-line in a hydrocracking pilot plant, as a noninvasive probe of the $\mathrm{H} / \mathrm{C}$ ratio enhancement chemical processes.

For determining the ash content, also calcium and iron oxides, in brown coal, a computer controlled probe based on XRF (x-ray fluorescence) and scattering of the low energy $x$ rays from a ${ }^{238} \mathrm{Pu}$ source is described by Antoniak et al. [96]. For ash content determination of washed coking coal on a conveyor belt, a dual energy gamma-ray transmission gauge was demonstrated by Gravitis et al. [97] over a 13-month trial period to measure ash contents in the $5 \%-10 \%(w t)$ range differing from chemical assays by $0.3 \%-0.4 \%$, and related techniques for on-line radiometric analysis and grading in mineral and coal processing are reviewed by Cutmore et al. [98]. An x-ray albedo gauge for determining ash in coal and coke, with correction for moisture content, has been described by Pandey and Prasad [99], and a combination x-ray transmission and albedo gauge "SIRO" (Scientific and Industrial Research Organization) for monitoring solids weight fraction and ash content of coal slurries of variable voidage has been demonstrated by Gravitis et al. [100]. Combination gamma-albedo and neutron-activation gauges have been developed by Holmes et al. [101] for on-stream (on conveyor belts) and bulk (in bins) analysis of iron ores to determine shale content and other information needed for ore grading. Holmes et a1. [101] also describe a gauge for determining the iron content in iron ores, in which the ore is irradiated by photons from ${ }^{226} \mathrm{Ra}$, and the $0.511 \mathrm{MeV}$ photons resulting from electron-positron pair production and annihilation are counted, based on principles developed by Sowerby and Ngo [102] and by Millen and Sowerby [103] for measuring ash content in coal.

\section{Radiometric Gauging and Control in the Agricultural and Forest Industries}

Radiometric gauging is used in all stages of the agricultural process, from snowpack profile radio- isotopic measurements (e.g., Smith et al. [104]) to radiometric monitoring and control of product packaging such as cottonwool bales for the bandage industry (Tabor et al. [105]). Fishman et al. [106] describe a soil moisture gamma-ray transmission gauge for use as a control unit for automatic irrigation in a field, also as a scanner for developing regional irrigation plans. A gamma-ray backscattering soil density gauge was demonstrated by Pirie et a1. [107], and Ertek and Haselberger [108] have developed a gamma multiple-scattering gauge for determining both density and water content in soil. For greater sensitivity to the soil moisture content, Ciftcioglu and Taylor [109] and Ciftcioglu et al. [110] describe a gamma-ray backscatter soil gauge with differential-mode counting. Neutron soil moisture gauges, including an analysis of the size of the region sampled by the device, are described by Kasi and Koskinen [111], Kasi [112], and by Kasi et al. [113]. Wilson [114] presents a parametric study of neutron backscattering soil moisture meters using transport theory.

Schätzler and Kühn [115] have developed a gamma-ray transmission and scanning device to measure and monitor the biomass in a field of growing plants, such as cereal grains, and Kühn [116] also describes a gamma-ray transmission device for monitoring the growth of individual agricultural products such as cabbage heads. In the latter application, the sawtooth growth curve of a cabbage head, from sprout to coleslaw, clearly revealed the biomass increase at night and loss during the day due to evaporation, also that wrapping the cabbage head in clear plastic for a segment of its life had no noticeable effect on this characteristic growth curve.

The moisture content of wheat is a critical parameter for the milling of wheat, and to achieve optimum milling performance it is usual to temper wheat to a set moisture content before milling, best done by using an on-line moisture measuring system to control the addition of water to the wheat. For this purpose a device for measuring both the moisture content and the density of the wheat by simultaneous neutron and gamma-ray transmission (NEUGAT technique) has been demonstrated by Bartle et al. [117], who also examined the merits of three different radiation sources: Am-Be (neutron mean energy $4.5 \mathrm{MeV}$, gamma-ray highest energies $4.4 \mathrm{MeV}$ ), an accelerator-base pulsed source (monoenergetic neutrons $4.5 \mathrm{MeV}$, gamma-ray mean energy $1.5 \mathrm{MeV}$ ), and ${ }^{252} \mathrm{Cf}$ (neutron mean energy 2 $\mathrm{MeV}$, gamma-ray mean energy $1 \mathrm{MeV}$ ). They concluded that the accelerator source has the highest figure of merit, followed by ${ }^{252} \mathrm{Cf}$ and ${ }^{241} \mathrm{Am}-\mathrm{Be}$, but 
that in practice the ${ }^{252} \mathrm{Cf}$ source may be preferred because of its simplicity. Another foodstuff monitoring radiometric device, described by Gläser et al. [118], is a two-energy $\left({ }^{241} \mathrm{Am}: 60 \mathrm{keV},{ }^{137} \mathrm{Cs}: 662\right.$ $\mathrm{keV}$ ) gamma-ray transmission gauge (KRAS-2), originally developed for ash content determination in lignite, to measure the amount of rocks and other mineral material accompanying potatoes on a conveyor belt transporting the potatoes into a storage facility.

In the forest industries, gamma-ray transmission gauges for determination of wood density and moisture content have been in use for some time, and a review of the early work has been given by Loos [119]. Now, densitometry and dendrochronology of tree cores are done routinely using scanning gamma transmission gauges, employing beam collimation widths as small as 0.1 mm to allow study of shapes as well as spacing of individual annual growth rings (e.g., Cown and Clement [120]). A somewhat different technique is described by Kouris et al. [121] in which a film is placed in contact with a thin slice of wood, and a radiograph of ring patterns is obtained using $x$ rays emitted from a source on the other side. The optical film density variations, according to Kouris et al. [121], can be related to chemical composition variations, as well as simple density variations. Liu et al. [122] and Olson et al. [123] have recently reviewed theoretical wood densitometry, including (1) [122] mass attenuation equations and (2) [123] optimal x-ray energy for wood density measurement. X-ray computed axial tomography (CAT), has also found its way into the forest industries, in a portable CAT device demonstrated and described by Onoe et al. [124] for measuring the water content and distribution in the annual rings of living trees, also for noninvasively examining the interiors of utility poles for deterioration.

In woodworking factory situations the wood byproducts and their physical characteristics are frequently of importance. For example, for measuring the moisture and density of bulk quantities of spruce chips, Korell et al. [125] have investigated gamma transmission gauges, and also gamma albedo gauges in the form of immersion probes, similar in geometry to the well-logging probes used in mineral exploration, inserted into barrels of chips.

\section{Radiometric Gauging and Control in Medicine and in the Medical Industries}

Concern over osteoporosis has resulted in the development of a variety of radiometric gauges for noninvasive measurement of bone mineral. Peppler and Mazess [126] and Mazess et al. [127] have developed a dual energy photon transmission method for measuring the total body bone mineral content as well as the total lean body mass. Smith et al. [128] have compared the accuracy of photon absorptiometry (or transmission) for local bone mineral measurements with that for neutron activation, and conclude that neutron activation offers somewhat better precision.

Photon scattering bone density gauges have been used in studies of osteoporosis and treatment effectiveness by Roberts et al. [129]. Assessments of dual energy Compton scatter densitometers, including the effects of multiple scattering in both the object of interest and the overlying material, have been made by Huddleston and Weaver [130] and by Huddleston et al. [131]. Bone densitometers using the ratio of coherent to Compton scattering have been described by Stalp and Mazess [132] and by Shukla et al. [133].

Among the more exotic medical radioisotopic metrologies is a widely-used technique for studying the vibrations in the inner ear in which to the basilar membrane is attached a small radioactive source whose emission energies are Doppler-shifted to alter their transmissions through a fixed Mössbauer absorber, a technique pioneered by Johnstone and Boyle [134]. Kliauga and Khanna [135] examined the dose rate delivered to the inner ear in the course of such measurements, including a theoretical analysis which depended heavily on plaquesource radiation field formulas and tables, including exponential attenuation and buildup factor, given by Hubbell et al. [136] and by Hubbell $[137,138]$.

In the medical pharmaceutical industry, a gamma-ray attenuation technique is used for monitoring the packing uniformity of powders for compressed tablets and for filling capsules, as described by Woodhead et al. [139], Woodhead and Newton [140], and Charlton and Newton [141].

\section{Summary}

In summary, we see that radiometric gauging and control devices employ photons, chargedparticle beams, and neutrons in a great variety of both routine and some very specialized tasks. Some tasks, such as thickness control in hot rolling and forming of steel, and observation of the contents and status of sealed pipes and vessels, benefit particularly from the noncontact, nonintrusive nature of radiometric gauging and control. 
Many of the above examples of radiometric gauging techniques have been developed and/or exploited in developing countries. This trend will probably continue, with accompanying international health-safeguard studies and local legislation to minimize the risks inherent in radiation usage while optimizing the technical and economic benefits. In all countries, sophisticated microcomputer analysis will extract additional useful information from the output of such complex devices as borehole loggers with both gamma and neutron sources and albedo spectrometer-detectors, also making more complete use of secondary signals as projected by McMaster [142] for all nondestructive evaluation (NDE) devices. Due also to increasing computer capabilities and availability, computed tomography (CT) will find more use across the board in industrial, agricultural, and medical situations, providing structural image information as well as density, thickness, and other parameters given by present radiation transmission and scatter gauges (Gilboy [143], Reimers et al. [144], and Vetter et al. [145]). However, process control in steel rolling and other hot fabrications, also in the paper and fabric industries, will likely continue to be dominated by present radiometric techniques through the remainder of the 1990s. In general, as pointed out by Charlton [146], radiation metrology will continue to gain favor with instrument engineers who are finding that nucleonic instruments, for a variety of special measurement problems, possess advantages offered by no other type of instrumentation.

\section{Acknowledgment}

The author particularly thanks D. K. Trubey, S. S. H. Kasi, and P. Lahure, also a considerable number of other researchers among those listed in the references below, for their assistance in preparing this review.

\section{References}

[1] Taylor, D., Radio-Isotope Instrumentation, IEE Reviews 118, 1090-1106 (1971).

[2] Palmer, R. B. J., Nucleonic Instrumentation Applied to the Measurement of Physical Parameters by Means of Ionising Radiation, J. Phys. E: Sci. Instrum. 15, 873-883 (1982).

[3] Bock, H., Applications of Radionuclides in Nuclear Technology. Summary of Lectures Presented at the Polytechnic Institute, Hanoi, Viet Nam within the IAEA Project VIE/1/004, Rep. AIAU-83301 (1983).

[4] Snow, S. G., and Morris, R. A., Section 16: Radiation Gaging, in Nondestructive Testing Handbook, Bryant and McIntire, eds., 2nd ed., (American Society for Nondestructive Testing, 1985).

[5] Hubbell, J. H., Radiation Gauging, in Encyclopedia of Materials Science and Engineering (Pergamon, 1986), 4040-4042.

[6] Hubbell, J. H., Industrial, Agricultural, and Medical Applications of Radiation Metrology: Current Status and Prospects for the 1990's, Proceedings of the 6th Pacific Basin Nuclear Conference, Beijing, China (1987).

[7] Clayton, C. G., Some Comments on the Development of Radiation and Radioisotope Measurement Applications in Industry, Appl. Radiat. Isot. 41, 917-934 (1990).

[8] Kartashev, E. R., Nuclear Analytical Techniques and Instruments in Geology, Mining and Metallurgy, Proceedings of the 6th Pacific Basin Nuclear Conference, Beijing, China (1987).

[9] Salgado, J., Carvalho, F. G., Oliveira, C., Manteigas, J., Pinta, M., Talefe, A., Cruz, C., Neves, J., and Ambrosio, A., Design, Construction and Use of Nuclear Instrumentation in Portugal, Appl. Radiat. Isot. 41, 1057-1066 (1990).

[10] ISO, Radionuclide Gauges-Gauges Designed for Permanent Installation, International Organization for Standardization, Geneva, International Standard ISO 7205-1986(E) (1986).

[11] Heier, K., Radiometric Level-Gauging, Automatisierrungstechnische Praxis 27, 313-319 (1985).

[12] Urbanski, P., Mathematical Models and Accuracy of Radioisotope Gauges, Nukleonika 34, 125-137 (1989).

[13] Urbanski, P., A Review of Calibration Procedures of Radiometric Gauges, Appl. Radiat. Isot. 41, 151-157 (1990).

[14] Henderson, I. A., and McGhee, J., Validation of Single Scatter Model for Backscatter Density Gauges, Mathl. Comput. Modelling 11, 1122-1127 (1988).

[15] Notea, A., and Segal, Y., A General Approach to the Design of Radiation Gauges, Nucl. Technol. 24, 73-80 (1974).

[16] Notea, A., and Segal, Y., Resolving Power of Dynamic Radiation Gauges, Nucl. Technol. 63, 121-128 (1983).

[17] Zav'yalkin, F. M., and Osipov, S. P., Effect of the Instability of Parameters of Bremsstrahlung Beams on the Accuracy of Radiometric Measurements, Defektoskopiya, No. 2, 36-40 (1989).

[18] Kasi, S. S. H., Consideration for Evaluation and Design of Radiation Gauges, Helsinki Univ. of Technology Report P5 (1981).

[19] Bernhardt, R., State and Trends of Development for Radiometric Unit Area Weight Measuring Technique, Isotopenpraxis 20, 119-126 (1984).

[20] Oyedele, J. A., Non-Instrumental Error in Continuous Radiogauging, Int. J. Appl. Radiat. Isot. 33, 1465-1469 (1982).

[21] Oyedele, J. A., The Bias in On-Line Thickness Calibration by Radiation Transmission, Nucl. Instr. Meth. 127, 507-514 (1983).

[22] Hubbell, J. H., Photon Mass Attenuation and Energy-Absorption Coefficients from $1 \mathrm{keV}$ to $20 \mathrm{MeV}$, Int. J. Appl. Radiat. Isot. 33, 1269-1290 (1982).

[23] Berger, M. J., and Hubbell, J. H., XCOM: Photon Cross Sections on a Personal Computer, National Bureau of Standards Rep. NBSIR 87-3597 (1987).

[24] Cullen, D. E., Chen, M. H., Hubbell, J. H., Perkins, S. T., Plechaty, E. F., Rathkopf, J. A., and Scofield, J. H., Tables and Graphs of Photon-interaction Cross Sections from $10 \mathrm{eV}$ to $100 \mathrm{GeV}$ Derived from the LLNL 
Evaluated Photon Data Library (EPDL). Part A: $Z=1$ to 50, and Part B: $Z=51$ to 100 , Lawrence Livermore National Laboratory Report No. UCRL-50400, Vol. 6, Rev. 4 (1989).

[25] Taylor, D., and Kansara, M., A Theory of the Nuclear Densimeter, Soil Science 104, 25-34 (1967).

[26] Taylor, D., and Kansara, Measuring Density with the Nuclear Back-scatter Method, Nucleonics 24, No. 6, 54-56 (1966).

[27] Pandey, H. D., Compton Scattering of X-Rays: Some Observations, X-Ray Spectrom. 13, 192-194 (1984).

[28] Gayer, A., Bukshpan, S., and Kedem, D., In Situ Density Measurement in Aqueous Solutions by the Gamma-Ray Backscattering Method, Nucl. Instr. Meth. 192, 619-621 (1982).

[29] Zabrodskii, V. A., Density Measurements on a Thin Material from X-ray Backscattering, Defektoskopiya, No. 8, 53-59 (1988).

[30] Zabrodskii, V. A., Density Measurement on a Material Having a Complex Composition from X-ray Backscattering, Defektoskopiya, No. 1, 15-19 (1989).

[31] Zabrodskii, V. A., Light Material Thickness Measurement from Soft X-ray Backscattering, Defektoskopiya, No. 9, 19-23 (1989).

[32] Golikov, E. G., Vasnin, G. M.,, Kovyazin, Yu. A., Kharitonov, Yu. S., Zakatov, M. M., and Fekhardinov, Scope for Identifying Materials in Multilayer Structures by Gamma-Ray Backscattering Methods, Defektoskopiya, No. 7, 63-67 (1985).

[33] Mohammadi, H., Thickness Gauging with Scattered Beta, Gamma, and X-Rays, Int. J. Appl. Radiat. Isot. 32, 524526 (1981).

[34] Saneyoshi, K., Itoh J., Toriyama, T., and Hisatake, K., Use of Ge-71 Source for Thickness Measurement of Thin Films, Nucl. Instr. Meth. 188, 253-256 (1981).

[35] Pekarski, G. Sh, Physical Principles of Neutron-Gamma Materials Monitoring, Defektoskopiya, No. 7, 54-62 (1985).

[36] Semenov, S. V., Determination of the Parameters of Porous Materials with the Aid of Positron Annihilation, Defektoskopiya, No. 5, 75-78 (1985).

[37] Lahure, P., Determination of Thickness Variations by Measuring Film Densities on Two Adjacent Areas of a Radiograph, Materials Evaluation 43, 354-356 (1985).

[38] Berger, H., editor, Practical Applications of Neutron Radiography and Gaging, American Society for Testing and Materials (ASTM) Special Publication 586 (1976).

[39] Morgan, I. L., Real-Time Digital Gauging for Process Control, Appl. Radiat. Isot. 41, 935-942 (1990).

[40] Martz, H. E., Azevedo, S. G., Brase, J. M., Waltjen, K. E., and Schneberk, D. J., Computed Tomography Systems and Their Industrial Applications, Appl. Radiat. Isot. 41, 943-961 (1990).

[41] Seshadri, M. D., Miller, D. W., Campbell, D., and Hill, J. M., Tomography Using a Diode-Array Digital Radiographic System, Appl. Radiat. Isot. 41, 963-966 (1990).

[42] Altukhov, A. A., Gusev, E. A., and Dzhikaev, Yu. K., Reconstructive Computer-Aided Tomography in Dynamic-Process Research (Review), Defektoskopiya, No. 1, 3-15 (1989).

[43] Gusev, E. A., Firstov, V. G., Petushkov, A. A., Musyankov, S. I., Ptitsyn, V. N., Chelnokov, V. B., Schastlivtsev, A. M., and Sosnin, F. R., A Scanning XRay Flaw Detector Containing a One-Dimensional Silicon-Detector Matrix, Defektoskopiya, No. 7, 38-42 (1989).
[44] Apelblat, A., A Continuous Level Gauge with the Linear Response for Cylindrical Vessels, Atomkern.-Kerntechn. 36, 98-101 (1980)

[45] Amberger, E., and Heier, K., Radiometric Level Measurement, Technische Messen. 51, 318-323 (1984).

[46] Ochiana, G., Oncescu, M, and Popescu, C., Radiometric Design of the Level Control Instruments Based on Gamma Photon Backscattering, Rev. Roum. Phys. 28, 489-497 (1983).

[47] Mathew, P. J., Ceravolo, C., Huppert, P., and Miles, J. G., A Continuous Neutron Level Gauge, Int. J. App1. Radiat. Isot. 34, 1377-1382 (1983).

[48] Gläser, M., and Emmelmann, K.-P., A Radiometric Liquid Level Gauge with Linear-Detection, Isotopenpraxis 9, 318-322 (1973).

[49] Dickstein, P., and Notea, A., Resolving Power of Radioactive Solution Level Gauging, Nucl. Instr. Meth. A252, 95-100 (1986).

[50] Thyn, J., and Pokorny, J., Spatial Distribution Studies of Milling Particles, Milling Charge, and Grist, Int. J. Appl. Radiat. Isot. 31, 179-185 (1980).

[51] Kondic, N. N., and Lassahn, G. D., Nonintrusive Density Distribution Measurement in Dynamic High-Temperature Systems, Instrum. Soc. Am. Trans. 19, 11-20 (1980).

[52] Frevert, E., A New Method for Non-Contact Measurement of the Wall Strength of Steel Tubes by Means of Radioactive Isotope, Isotopenpraxis 17, 301-305 (1981).

[53] Frevert, E., Method of Non-Contacting Gauging of the Wall Thickness of Tubes by Backscatter of Ionizing Radiation, Atomkernen.-Kerntechn. 48, 87-90 (1986).

[54] Kapranov, B. I., Myakin'kova, L. V., and Shaverin, V. A., Radioisotope Albedo Thickness Gauging of Polymer Coatings on a Metallic Substrate, Defektoskopiya, No. 4, 10-15 (1986).

[55] Grupper, A. R., Positron Coating Thickness Measurement, Defektoskopiya, No. 8, 29-33 (1986).

[56] Salmi, M., Magrini, A., Gigante, G. E., and Barra, O. A., Coating Thickness Measurement by Means of the Radioisotope X-Ray Fluorescence Technique, Isotopenpraxis 14, 380-381 (1978).

[57] Singh, S. P., Kaushik, D. K., Chattopadhyaya, S. K., and Nath, N., Thickness Measurements of Single and Composite Thin Metal Films Using the X-Ray Fluorescence Technique, Thin Solid Films 59, 51-55 (1979).

[58] Kaushik, D. K., Singh, S. P., Bhan, C., Chattopadhyaya, S. K., and Nath, N., Thickness Determination of Ultrathin Metal Films Using the X-Ray Fluorescence Technique, Thin Solid Films 67, 353-356 (1980).

[59] Luzzi, G., Mazzei, A., Neri, A., Salmi, M., and Spagnolo, G. S., Measurement of Thin Film Thickness by Means of a Simple Non-Destructive Radioisotopic Technique, Thin Solid Films 67, 347-351 (1980).

[60] Kowalska, E., and Urbanski, P., Radiometric Method and Instrument for Determination of Thickness and Composition of $\mathrm{Sn}-\mathrm{Pb}$ Platings and Galvanic Bath Analysis, Nukleonika 32, 131-145 (1987).

[61] Miranda, J., Oliver, A., and Montenegro, E. C., A New Method for Thin-Film Thickness Measurement Using PIXE, Nucl. Instr. Meth. B43, 203-209 (1989).

[62] Oliver, A., and Miranda, J., A Comparison Between PIXE and RBS Thin Film Measurements in Binary Targets, Nucl. Instr. Meth. B29, 521-526 (1987).

[63] Tabor, P., Molnar, L., and Nagymihalyi, D., Microcomputer Based Thickness Gauges, Appl. Radiat. Isot. 41, 1123-1129 (1990) 
[64] Petushkov, A. A., Gusev, E. A., Egorov, I. V., Maslov, A. I., and Sokolov, V. A., Analog Method of Linearizing the Transmission Function in X-Ray Equipment for Measuring the Thickness of Rolled Stock, Defektoskopiya, No. 10, 39-44 (1989).

[65] Firstov, V. G., Portnov, L. A., Sokolov, V. A., and Egorov, I. V., The State of the Art and Development Prospects of X-Ray Measurement of Rolled Sheet, Defektoskopiya, No. 12, 45-51 (1987).

[66] Mirowicz, J., and Lis, L., Industrial Application of Neutron Gauges for Measuring Acid Concentrations, Nukleonika 34, 19-26 (1989).

[67] Stopporka, J., Häussler, F., and Langrock, E.-J., Film Thickness Measurements of Liquid Layers by Using Open Radionuclides, Isotopenpraxis 22, 356-361 (1986).

[68] Donhoffer, D. K., On-Stream Analysis by Means of Energy-Dispersive X-Ray Fluorescence, Atomkernen.Kerntechn. 44, 266-268 (1984).

[69] Oyedele, J. A., Spatial Effect in Radiation Diagnosis of Two-Phase-Flow Systems, Int. J. Appl. Radiat. Isot. 35, 865-873 (1984).

[70] Oyedele, J. A., The Dynamic Bias in Void Fraction Determination in Liquid Flow Systems by Radiation Attenuation Techniques, Atomkernen.-Kerntechn. 49, 165-167 (1987).

[71] Lin, T. F., Block, R. C., Jones, O. C., Lahey, R. T., and Murase, M., Measurement of Flow in a Horizontal Pipe Using the Pulsed Photon Activation Technique, Nucl. Sci. Eng. 91, 235-247 (1985).

[72] Wang, C.-Y., and Shih, C., Void Fraction Measurements by Scintillation Counting Technique, Nucl. Sci. J. (Taiwan) 27, 79-80 (1990).

[73] Hussein, E. M. A., Modelling and Design of a Neutron Scatterometer for Void-Fraction Measurement, Nucl. Eng. Design 105, 333-348 (1988).

[74] Hussein, E. M. A., and Waller E. J., A Neutron SteamQuality Meter for a Fluidized Bed Plant, Appl. Radiat. Isot. 41, 1049-1055 (1990).

[75] Entine, G., Afshari, S., and Verlinden, M., Nondestructive Evaluation of Reinforced Plastics by a Radiometric Measurement Method, Appl. Radiat. Isot. 41, 1117-1122 (1990).

[76] Rikard, R. D., and Streit, R. D., Radiographic Techniques to Characterize the Absorption of Liquid into a Foam, Mater. Eval. 45, 1419-1422 (1987).

[77] Singh, J. J., Mall, G. H., Sprinkle, D. R., and Chegini, H., Feasibility of a Nuclear Gauge for Fuel Quantity Aboard Aircraft, National Aeronautics and Space Administration, Langley Research Center, Hampton, VA, NASA Techn. Mem. 87706 (1986).

[78] Singh, J. J., Low-Energy Gamma-Ray Absorption Characteristics of Aviation Fuels, Trans. Am. Nucl. Soc. 60, 211-212 (1989).

[79] Groshev, V. Ya., and Zabrodski, V. A., Measurement of the Density of Solids on the Basis of Backscattering of $\mathrm{X}$ Radiation, Defektoskopiya, No. 8, 52-59 (1985).

[80] Adil, N., The Measurement of Concrete Density by BackScattered Gamma Radiation, Brit. J. of NDT, 72-77 (March 1977).

[81] Dunn, W. L., and Hutchinson, J. E., A Nuclear Technique for Thin-Lift Gauging, Int. J. Appl. Radiat. Isot. 33, 563-567 (1982).

[82] Fookes, R. A., Watt, J. S., Seatonberry, B. W., Davison, A., Greig, R. A., Lowe, H. W., and Abbott, A. C.,
Gamma-Ray Backscatter Applied to the On-Line Location of Termite-Damaged Railway Sleepers, Int. J. Appl. Radiat. Isot. 29, 721-728 (1978).

[83] Rohella, R. S., Measurement of Concentration and Concentration Gradient in Slurry Pipeline Using Gamma-Ray Technique, Indian J. Technol. 26, 260-264 (1988).

[84] Henderson, I. A., and McGhee, J., Modelling GammaSource Backscatter Density Gauges, IEE Proc. 133, 611617 (1986).

[85] Henderson, I. A., and McGhee, J., A Null Balance Technique for Backscatter Density Gauges, IEEE Trans. on Nucl. Sci. 35, 1055-1060 (1988).

[86] Hussein, E. M. A., and Whynot, T. M., A Compton Scattering Method for Inspecting Concrete Structures, Nucl. Instr. Meth. A283, 100-106 (1989).

[87] Tuzi, S., and Sato, O., Locating the Positions of Reinforcing Bars in Reinforced Concrete Using Backscattered Gamma Rays, Appl. Radiat. Isot. 41, 1013-1018 (1990).

[88] Hubbell, J. H., Common Volume of Two Intersecting Cylinders, J. Res. Nat1. Bur. Stand. (U.S.) 69C, 139-143 (1965).

[89] Watt, J. S., Application of Radioisotope Techniques to the Mineral Industry, Trans. Am. Nucl. Soc. 49 (S-1), 411-422 (1985), Proc. 5th Pacific Basin Nuclear Conf., Seoul, Korea 1985.

[90] Bertozzi, W., Ellis, D. V., and Wahl, J. S., The Physical Foundation of Formation Lithology Logging with Gamma Rays, Geophys. 46, 1439-1455 (1981).

[91] Entine, G., Tiernan, T., Waer, P., and Hazlett, T., Coal Mining Applications of CdTe Gamma Ray Sensors, Appl. Radiat. Isot. 41, 1019-1021 (1990).

[92] Holmes, R. J., On-Stream and Bulk Analysis of Iron Ores, Bull. Proc. Australas. Inst. Min. Metall. 290, 99-103 (1985).

[93] Borsaru, M., Holmes, R. J., and Mathew, P. J., Bulk Analysis Using Nuclear Techniques, Int. J. Appl. Radiat. Isot. 34, 397-405 (1983).

[94] Gordon, C. M., and Peters, C. W., A Fast-Neutron Probe for Tomography and Bulk Analysis, Appl. Radiat. Isot. 41, 1111-1116 (1990).

[95] Liu, D. D. S., and Patmore, D. J., Application of GammaRay Densitometry in Developing Primary Upgrading Processes, Appl. Radiat. Isot. 41, 1003-1012 (1990).

[96] Antoniak, W., Wagner, O., and Urbanski, P., A Laboratory Instrument for Determination of Ash in Brown Coal and Some Results of Its Testing, Nukleonika 34, 151-161 (1989).

[97] Gravitis, V. L., Watt, J. S., Muldoon, L. J., and Cochrane, E. M., Long-term Trial of a Dual Energy Gamma-Ray Transmission Gauge Determining the Ash Content of Washed Coking Coal on a Conveyor Belt, Nucl Geophys. 1, 111-124 (1987).

[98] Cutmore, N. G., Holmes, R. J., Sowerby, B. D., and Watt, J. S., Nuclear Techniques for On-Line Analysis in Mineral and Coal Processing, Proc. 13th Congr. of the Council of Mining \& Metallurgical Institutions, Singapore, May 11-16 (1986).

[99] Pandey, H. D., and Prasad, M. S., Effect of Moisture on the Accuracy of Coke-Ash Determination by X-Ray Backscattering, Spectrochim. Acta B39, 943-946 (1984).

[100] Gravitis, V. L., Watt, J. S., Zastawny, Z., Howells, E., and McLennan, T., Plant Trials of a SIRO Gauge for the Determination of Solids Weight Fraction and Ash Content of Coal in Slurries of Variable Voidage, Bull. Proc. Australas. Inst. Min. Metall. 291, 41-47 (1986). 
[101] Holmes, R. J., Roczniok, A. F., Rafter, P. T., and Sowerby, B. D., Grade Determination of Iron Ore Using Pair Production, Analyt. Chim. Acta. 152, 105-112 (1983).

[102] Sowerby, B. D., and Ngo, V. N., Determination of the Ash Content of Coal Using Annihilation Radiation, Nucl. Instr. Meth. 188, 429-437 (1981).

[103] Millen, M. J., and Sowerby, B. D., Correction of Pair Production Gauge Ash Determinations for Changes in Coal Ash Composition, Int. J. Appl. Radiat. Isot. 36, 627-633 (1985).

[104] Smith, J. L., Willen, D. W., and Owens, M. W., Measurement of Snowpack Profiles with Radioactive Isotopes, Weatherwise, 247-257 (December 1965).

[105] Tabor, P., Molnar, J., and Nagymihalyi, D., Radioisotope Gauge for Automatic Control of Cottonwool Package, Acta Imiko (Hungary), 377-384 (1979).

[106] Fishman, A., Notea, A., and Segal, Y., Gamma Transmission Gauge for Assay of Integral Water Content in Soil, Nucl. Instr. Meth. 184, 571-576 (1981).

[107] Pirie, E., Lin, K., and Taylor, D., Soil Density Measurements with Gamma-Rays, Soil Sci. 106, 411-414 (1968).

[108] Ertek, C., and Haselberger, N., Measurement of Density and Water Content of Soil Using Photon Multiple Scattering, Nucl. Instr. Meth. 227, 182-185 (1984).

[109] Ciftcioglu, O., and Taylor, D., A Gamma-Backscatter Density Gauge with Differential-Mode Counting, Nucl. Instr. Meth. 94, 53-59 (1971).

[110] Ciftcioglu, O., Byatt, D. A., and Taylor, D., Determination of Moisture Content with a Gamma Backscatter Density Gauge, J. Soil Sci. 23, 32-37 (1972).

[111] Kasi, S. S. H., and Koskinen, H., Analysis, Calculations and Measurements Concerning the Moisture Measuring by the Neutron Method, Nucl. Eng. Design 3, 74-82 (1966).

[112] Kasi, S. S. H., An Attempt to Calculate Correctly the Region of Influence in Gauging Moisture with Neutrons, Int. J. Appl. Radiat. Isot. 33, 667- (1982).

[113] Kasi, S. S. H., Immonen, J., and Saikku, K., Some Considerations for Soil Moisture with Neutrons, Helsinki Univ. of Technol. Lab. of Physics Rep. 120 (1983).

[114] Wilson, D. J., Neutron Moisture Meters: The Effects of Various Soil Parameters, Nucl. Technol. 60, 155-163 (1983).

[115] Schätzler, H. P., and Kühn, W., Growth Studies on Plant Plots by Gamma Scanning, Int. J. Appl. Radiat. Isot. 28, 645-652 (1977).

[116] Kühn, W., New Radiometric and Radioanalytical Methods in Agricultural Research, Atomic Energy Review 16, 619-655 (1978).

[117] Bartle, C. M., Purcell, C. R., and Wilson, A., Determination of the Moisture Content of Wheat, Using the NEUGAT Technique, Nucl. Instr. Meth. A291, 655-661 (1990).

[118] Gläser, M., On-line Measurements of Mineral Admixtures at an Entrance Conveyor Belt of a Potato Storage Facility by a 2-Energy Gamma-ray Transmission Gauge, Isotopenpraxis 23, 58-64 (1987).

[119] Loos, W. E., The Relationship between Gamma-ray Absorption and Wood Moisture Content and Density, Forest Products J., 145-149 (March 1961).

[120] Cown, D. J., and Clement, B. C., A Wood Densitometer Using Direct Scanning with X-Rays, Wood Sci. Technol. 17, 91-99 (1983).

[121] Kouris, K., Tout, R. E., Gilboy, W. B., and Spyrou, N. M., Effect of Constituent Elements in Wood on X-Ray
Densitometry Measurements, Archaeometry 23, 95-101 (1981).

[122] Liu, C. J., Olson, J. R., Tian, Y., and Shen, Q., Theoretical Wood Densitometry: I. Mass Attenuation Equations and Wood Density Models, Wood and Fiber Sci. 20, 22-34 (1988).

[123] Olson, J. R., Liu, C. J., Tian, Y., and Shen, Q., Theoretical Wood Densitometry: II. Optimal X-ray Energy for Wood Density Measurement, Wood and Fiber Sci. 20, 187-196 (1988).

[124] Onoe, M., Tsao, J. W., Yamada, H., Nakamura, H., Kogure, J., Kawamura, H., and Yoshimatsu, M., Computed Tomography for Measuring the Annual Rings of a Live Tree, Nucl. Instr. Meth. 221, 213-220 (1984).

[125] Korell, U., Kurth, H., and Mette, H.-J., Radiometric Measurements of Moisture and Density in Spruce Chips, Isotopenpraxis 21, 220-223 (1985).

[126] Peppler, W. W., and Mazess, R. B., Total Body Bone Mineral and Lean Body Mass by Dual-Photon Absorptiometry. I. Theory and Measurement Procedure, Calcif. Tissue Int. 33, 353-359 (1981).

[127] Mazess, R. B., Peppler, W. W., Chesnut, C. H., Nelp, W. B., Cohn, S. H., and Zanzi, I., Total Body Bone Mineral and Lean Body Mass by Dual-Photon Absorptiometry. II. Comparison with Total Body Calcium by Neutron Activation Analysis, Calcif. Tissue Int. 33, 361-363 (1981).

[128] Smith, M. A., Elton, R. A., and Tothill, P., The Comparison of Neutron Activation Analysis and Photon Absorptiometry at the Same Part-Body Site," Clin. Phys. Physiol. Meas. 2, 1-7 (1981).

[129] Roberts, J. G., Lien, J. W. K., Woolever, C. A., and Webber, C. E., Photon Scattering Measurements of Calcaneal Bone Density: Results of In Vivo Longitudinal Studies, Clin. Phys. Physiol. Meas. 5, 193-200 (1984).

[130] Huddleston, A. L., and Weaver, J. B., Dual-Energy Compton Scatter Densitometry, Int. J. Appl. Radiat. Isot. 34, 997-1002 (1983).

[131] Huddleston, A. L., Posteraro, R. H., Sackler, J. P., and Dunn, S. E., Determination of Multiple- and SingleScatter Fractions in Compton-Scatter Densitometry, Int. J. Appl. Radiat. Isot. 37, 1095-1102 (1986).

[132] Stalp, J. T., and Mazess, R. B., Determination of Bone Density by Coherent-Compton Scattering, Med. Phys. 7, 723-726 (1980).

[133] Shukla, S. S., Leichter, I., Karellas, A., Craven, J. D., and Greenfield, M. A., Trabecular Bone Mineral Density Measurement In Vivo: Use of the Ratio of Coherent to Compton-Scattered Photons in the Calcaneus, Radiol. 158, 695-697 (1986).

[134] Johnstone, B. M., and Boyle, A. J. F., Basilai Membrane Vibration Examined with the Mössbauer Technique, Science 158, 389-390 (1967).

[135] Kliauga, P., and Khanna, S. M., Dose Rate to the Inner Ear During Mössbauer Experiments, Phys. Med. Biol. 28, 359-366 (1983).

[136] Hubbell, J. H., Bach, R. L., and Lamkin, J. C., Radiation Field from a Rectangular Source, J. Res. Natl. Bur. Stand. (U.S.) 64C, 121-138 (1960).

[137] Hubbell, J. H., Dose Fields from Plane Sources Using Point-Source Data, Nucleonics 21, No. 8, 144-148 (1963).

[138] Hubbell, J. H., A Power-Series Buildup Factor Formulation. Application to Rectangular and Off-Axis Disk Source Problems, J. Res. Natl. Bur. Stand. (U.S.) 67C, 291-306 (1963). 
[139] Woodhead, P. J., Hardy, J. G., and Newton, J. M., Determination of Porosity Variations in Powder Beds, J. Pharm. Pharmacol. 34, 352-358 (1982).

[140] Woodhead, P. J., and Newton, J. M., The Influence of Deposition Method on the Packing Uniformity of Powder Beds, J. Pharm. Pharmacol. 35, 133-137 (1983).

[141] Charlton, B., and Newton, J. M., Application of Gamma-Ray Attenuation to the Determination of Density Distributions within Compacted Powders, Powder Technol. 41, 123-134 (1985).

[142] McMaster, R. C., A Look Ahead at Nondestructive Testing, Brit. J. of NDT, 351-356 (Nov. 1986).

[143] Gilboy, W. B., X- and Gamma-Ray Tomography in NDE Applications, Nucl. Instr. Meth. 221, 193-200 (1984).

[144] Reimers, P., Gilboy, W. B., and Goebbels, J., Recent Developments in the Industrial Application of Computerized Tomography with Ionizing Radiation, NDT Int. 17, 197-207 (1984).

[145] Vetter, J. R., Perman, W. H., Kalender, W. A., Mazess, R. B., and Holden, J. E., Evaluation of a Prototype Dual Energy Tomographic Apparatus. II. Determination of Vertebral Bone Mineral Content, Med. Phys. 13, 340343 (1986).

[146] Charlton, S., The Application of Nucleonic Instruments in Measurement and Control, The Chem. Engineer, No. 406, 49-51 (1984).

About the Author: John $H$. Hubbell, recently retired from NIST, began his career in the NBS/NIST Junior Scientist Rotation Training Program, serving in the X-Ray Crystal Diffraction and Thermodynamics Groups. He served the balance of his career in the NBS/NIST Radiation Theory Group, now part of the Radiation Interactions and Dosimetry Group, Ionizing Radiation Division, Center for Radiation Research, National Measurement Laboratory. 